\title{
What determines walking of older people in their neighborhood?
}

\author{
Marijke Hopman-Rock ${ }^{1,2^{*}}$, Sanne I. de Vries ${ }^{1}$, Ingrid Bakker ${ }^{1,3}$, Wil T. M. Ooijendijk ${ }^{1}$ \\ ${ }^{1}$ Lifestyle Expertise Center, TNO Netherlands Organisation for Applied Scientific Research, Leiden, The Netherlands; \\ *Corresponding Author: marijke.hopman@tno.nl \\ ${ }^{2}$ Body@Work, Research Center, TNO VU University Medical Center, Amsterdam, The Netherlands \\ ${ }^{3}$ Windesheim University of Applied Science, Zwolle, The Netherlands
}

Received 17 April 2012; revised 26 May 2012; accepted 28 June 2012

\section{ABSTRACT}

Based on literature review and five focus groups, a model was analyzed describing individual, social environmental and physical environmental (perceived) determinants of walking by older people. Aim was to test whether these determinants were significantly associated with the duration of walking by older people ( $N=567,50$ 80 years) in a middle-sized Dutch town. Walking time was best predicted by attitude towards walking (partial correlation in model (partial $r$ ) $0.18 ; p<0.05$ ), social contacts (partial $r 0.12, p<$ 0.05 ), perceived quality of life (partial $r 0.21, p<$ 0.01 ), satisfaction with the demographics of the neighborhood (partial $r-0.14, p<0.01$ ), and walking outside the neighborhood (partial $r$ 0.28, $p<0.01$ ). The model explained $20 \%$ of the total variance in walking time. Conclusion is that individual and social determinants predicted the most variance in walking time and that perceived environmental determinants played only a minor role. Health promotion actions may benefit from these insights.

Keywords: Older Adults; Physical Activity; Environment; Health; Determinants

\section{INTRODUCTION}

The composition of the Dutch population will change drastically over the coming decades. This is partly due to increased life expectancy and the aging "baby boomer generation", also known as "double aging”. In 2035 it is expected that a quarter (25.1\%) of the Dutch population is 65 years or older. Adequate physical activity has many positive effects on health. It is known to reduce the risk of cardiovascular disease, diabetes, osteoporosis and obesity [1,2]. Physical activity also has a beneficial ef- fect on the course of several chronic diseases [3], cognition [4-6], welfare [7], physical functioning, and independence [8,9]. Many older people have insufficient physical activity for maintaining good health. The Dutch Standard for Healthy Physical Activity (NNGB) suggests that at least five days a week at least 30 minutes daily of moderate intensity physical activity should be performed to maintain and improve health [10]. This recommendation however, is not achieved by many older people in the Netherlands: $42.5 \%$ of the 65 - to 74 -year-olds and $56.5 \%$ of the over-75 s in 2008/2009 did not meet the NNGB [11]. One of the ways to meet the standards could be fulfilled by walking. Walking is the most feasible form of physical activity for older people. Together with swimming, cycling and gymnastics it is most popular [12]. Also, the risk of injuries is minimal compared to sports activities. To promote health and quality of life of older people, it is important to examine why older people may or may not walk, what kind of neighborhood characteristics are associated with walking, and what measures could be taken to encourage walking. Based on literature $[13,14]$ and focus group interviews with older people [15] we analyzed a model (see Figure 1) to explain the neighborhood walking behavior of independently living older people (50 - 80 years).

\section{METHOD}

The model was tested among independently living older people (50 - 80 years), both native and immigrants in Schiedam (a Dutch middle size town). The protocol has been checked by the TNO medical ethic committee.

\subsection{Selected Neighborhoods}

For the study, three post-war neighborhoods were selected, similar in population composition (percentage of older natives and immigrants) and different in their physical environment (e.g. green areas, type of housing). This guaranteed us enough generalizability for this town. 


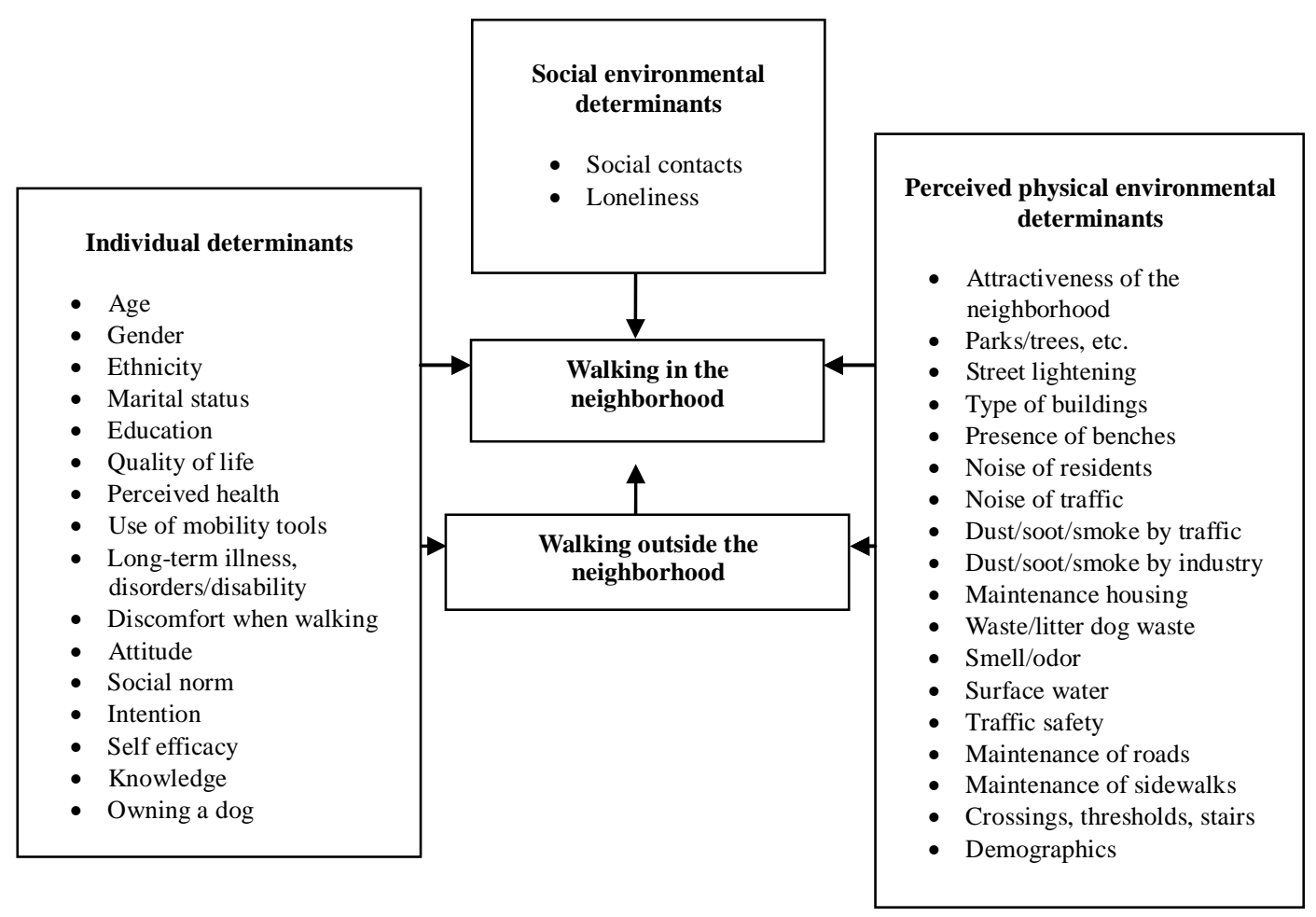

Figure 1. Model for walking in the neighborhood by older people.

\subsection{Questionnaire}

Based on five focus group interviews [15] with a total of 47 older people, a written questionnaire was developed and distributed by regular mail among 1800 older people (600 per neighborhood). The sample was provided by the municipality of Schiedam. The sample was stratified on age (classes of 5 years). For immigrants, a lower age (from 50 years) was allowed due to cultural differences such as having children at a relatively young age and the fact that immigrants of the first generation had low absolute numbers. Per family one person was invited to respond. To increase the response rate, the questionnaire was distributed using the town mail and picked up personally. People who were not at home were asked to send the questionnaire back using a pre-addressed return envelope. In the questionnaire, in addition to data on the walking duration and frequency, data on personal characteristics (e.g. age, gender, perceived health), social environment (e.g. social network, loneliness) and physical environment (including satisfaction with safety, litter, maintenance of sidewalks, etc.) was collected (see Figure 1). Furthermore, questions were included on ethnicity, socioeconomic status, physical disability, dog ownership and social cognitive factors such as attitude, social norm and intention with respect to "walking in the neighborhood". At the time the study was carried out, no standard questionnaires were yet available about walkability. Quality of life was determined by the physical functioning scale from the RAND-36 (scale scores 1 100) [16]. As a measure of readiness for walking and being a potential confounder, the frequency and duration of walking outside the neighborhood was also determined. Duration per walking motive (pleasure, shopping, health care, etc.) was asked using 4 categories (less than 5 minutes, between 5 to 10 minutes, between 10 to 20 minutes, more than 20 minutes; either: $<10$ minutes, 10 20 minutes, 20 - 30 minutes, $>30$ minutes), walking was asked in 6 frequency categories ranging from daily to $<1$ time per month. Duration and frequency of the components were then combined into a total walking time score. The whole questionnaire in Dutch is available from the first author.

\subsection{Analysis}

The questionnaires were entered and analyzed using the statistical program SPSS. We used descriptive statistics to characterize the study population and to describe walking behavior. To examine the univariate association between walking behavior (total minutes per week) and all determinants, Pearson correlations were calculated (if possible). Using a stepwise multivariate regression analysis, we examined the percentage of the variance in total walking time in the neighborhood that could be explained by the determinants. Variables were introduced in blocks: individual determinants, social environment, physical environment, walking outside the neighborhood 
(as possible confounder). All analyses were corrected for multi-collinearity (>0.89) and skewed variables (skewedness smaller or larger than 1). Since self-efficacy was only assessed in a sub-set (the group that walked), this variable was removed from the model.

The original walking time values (dependent variable) were recoded as follows: $2.5=$ less than 5 minutes, $5=$ less than 10 minutes, 7.5 = between 5 - 10 minutes, $15=$ between 10 to 20 minutes, 25 = between 20 - 30 minutes, 35 = more than 30 minutes. For frequency: $0=$ never, 0.125 = less than once a month, $0.25=$ once a month, 0.5 = once every two weeks, 1 = once a week, 3 = several times a week, 6 = daily.

Coding of independent variables was as follows. Gender: 0 = female, $1=$ male; Ethnicity: $0=$ immigrant $1=$ native; Marital status: $0=$ living alone, $1=$ lives together; Education $(1-6)$ : lowest $=1$ highest $=6$ (as dummies included because there is no linear relationship, see table); Perceived health (1 - 5): 1 = poor to 5 = excellent; Mobility aid: $0=$ no, 1 = yes; Chronic illness: $0=$ no, $1=$ yes; Degree of limitations when walking: sum score of questions (0 - 48); Attitude: $1=$ annoying $2=$ neutral $3=$ nice; Social norm: 0 - 2; Intention: $(0-4) 0=$ low, $4=$ high; Knowledge: sum score of six questions (0 - 6); Owner of a dog: $0=$ no 1 = yes; Social contacts: 0 - 6, 6 = daily; Loneliness: 0 = not lonely, 2 = sometimes, 3 = always lonely; Attractiveness of the neighborhood: sum score 3 - 15, 15 = highest; Stage of change $(1-5): 1=$ not walking and no plans for change, $5=$ often walking and doing this a longer time already. Satisfaction with the environment was measured by 5 points scales (not at all to very satisfied). We used pairwise deletion of cases with missing values. P-values less than or equal to 0.05 were considered as statistically significant.

\section{RESULTS}

\subsection{Response}

Finally, 567 questionnaires were correctly completed and returned. This was a response rate of $32 \%$, which is customary in the municipality of Schiedam. The mean age of respondents was 68.1 years (SD: 6.9 years). Sixty percent was female. Nine percent was from ethnic minorities (immigrants). The majority of respondents lived for several years in Schiedam (M: 49 years, range: 2 - 81 years).

\subsection{Walking in the Neighborhood}

Of all 567 respondents, 94\% indicated to walk inside or outside the neighborhood. On average respondents walked more than two hours a week (144 minutes), including those not walking (see Table 1). Immigrants walked on average 105 minutes and native residents 128
Table 1. Overview of reasons for walking by study participants (Mean age 68.1 yrs., range 50 - 80 yrs., $N=567$ ).

\begin{tabular}{|c|c|}
\hline & $\begin{array}{l}\text { Mean (SD, if skewed } \\
\text { 25e to 75e percentile) }\end{array}$ \\
\hline \multicolumn{2}{|l|}{ Walking in the neighborhood } \\
\hline \multicolumn{2}{|l|}{ Walking for errands } \\
\hline Percentage yes & 84 \\
\hline Frequency per week ${ }^{\mathrm{a}}$ & $3.5(1.9)$ \\
\hline Duration per time (minutes) ${ }^{\mathrm{a}}$ & $11.7(6.1)$ \\
\hline Total time per week (minutes) ${ }^{\mathrm{a}}$ & $42.1(33.2)$ \\
\hline \multicolumn{2}{|l|}{ Walking for health or caring } \\
\hline Percentage yes & 65 \\
\hline Frequency per week $^{\mathrm{a}}$ & 1.1 \\
\hline Duration per time (minutes) ${ }^{\mathrm{a}}$ & $12.4(6.1)$ \\
\hline Total time per week (minutes) ${ }^{\mathrm{a}}$ & $15.0(1.9-15)$ \\
\hline \multicolumn{2}{|c|}{$\begin{array}{l}\text { Walking to neighbors, friends, family or other } \\
\text { persons }\end{array}$} \\
\hline Percentage yes & 68 \\
\hline Frequency per week ${ }^{\mathrm{a}}$ & 1.7 \\
\hline Duration per time (minutes) ${ }^{\mathrm{a}}$ & $12.2(6.7)$ \\
\hline Total time per week (minutes) ${ }^{\mathrm{a}}$ & $19.9(3.7-22.5)$ \\
\hline \multicolumn{2}{|l|}{ Walking with the dog } \\
\hline Percentage that owns a dog & 7 \\
\hline Frequency per week $^{\mathrm{a}}$ & $26.3(23.3)$ \\
\hline Duration per time (minutes) ${ }^{\mathrm{a}}$ & $24.1(9.3)$ \\
\hline Total time per week (minutes) ${ }^{\mathrm{a}}$ & $547.6(312.9)$ \\
\hline \multicolumn{2}{|c|}{ Walking for pleasure inside the neighborhood } \\
\hline Percentage yes & 61 \\
\hline Frequency per week ${ }^{\mathrm{a}}$ & $2.3(1.8)$ \\
\hline Duration per time (minutes) ${ }^{\mathrm{a}}$ & $29.9(7.1)$ \\
\hline Total time per week (minutes) $^{\mathrm{a}}$ & $69.5(59.9)$ \\
\hline $\begin{array}{l}\text { Total time walking in the neighborhood } \\
\text { (minutes) }\end{array}$ & $126.0^{\mathrm{b}} / 136.1^{\mathrm{a}}$ \\
\hline \multicolumn{2}{|l|}{ Walking outside the neighborhood } \\
\hline \multicolumn{2}{|c|}{ Walking for pleasure outside the neighborhood } \\
\hline Percentage yes & 54 \\
\hline Frequency per week ${ }^{\mathrm{a}}$ & 1.2 \\
\hline Duration per time (minutes) ${ }^{a}$ & $32.3(6.0)$ \\
\hline Total time per week (minutes) ${ }^{\mathrm{a}}$ & $37.4(6.2-35)$ \\
\hline $\begin{array}{l}\text { Total time walking in and outside the } \\
\text { neighborhood in minutes }\end{array}$ & $144.0^{\mathrm{b}} / 153.7^{\mathrm{a}}$ \\
\hline
\end{tabular}

Walking in the neighborhood

alking for errands

Percentage yes

king for health or caring

Percentage yes

Frequency per week

Total time per week (minutes)

Walking to neighbors, friends, family or other ersons

Percentage yes

Walking with the dog

Percentage that owns a dog

Duration per time (minutes) ${ }^{\mathrm{a}}$

$547.6(312.9)$

61

(1.1)

Duration per time (minutes)

Total time walking in the neighborhood (minutes)

${ }^{\mathrm{a}}$ Persons that do not walk (for this goal) are not included; ${ }^{\mathrm{b}}$ Including persons not walking. 
minutes a week. Walking is mostly to run errands or go shopping. Nearly $85 \%$ of the respondents walked for that purpose on average over 10 minutes at a time, and on average more than 40 minutes per week (see Table 1). In addition, more than $60 \%$ of older people walked sometimes for pleasure in the neighborhood, on average 2 to 3 times a week. Especially people who have dogs (7\% of respondents) walked a lot and often. Average walking the dog was around 9 hours a week (with a large variation from 3 hours to more than 20 hours per week).

About one in 10 respondents used a walking aid. In particular, the use of a walker (in $46 \%$ of these cases) and a cane (37\%) was mentioned.

Reasons to walk. There may be many reasons for walking. In the questionnaires the respondents could mention up to three reasons why they go somewhere on foot. "Get a breath of fresh air" and "staying fit" motivated more than half of the respondents. About one third of respondents mainly walked to enjoy nature and/or to relax; one in ten respondents walked because the doctor said it's good, because it is a good use of free time, or to meet other people. Respondents could also mention up to three reasons why they walk or not. Nineteen percent of the respondents indicated that they always walk. Of the remaining cases, a third walked because the destination is not too far. About twenty percent don't walk because of weather conditions or health problems and about ten percent don't walk mainly because other activities give more fun, they are afraid of falling, or have lack of time. Other reasons mentioned for not going somewhere by foot are: safety concerns (darkness, paving, violence) (3\%), heavy shopping bags (2\%) or a preference for bike or car (7\%).

Individual determinants. Of all individual determinants included in the model, the quality of life (Pearson correlation $r=0.22)$, perceived health $(r=0.13)$, the attitude towards walking ( $r=0.19)$ and the social norm (0.11) were positively (significant different from zero and above 0.10) univariate associated with the total walking time (sum score in minutes, see Table 2). Having a chronic illness, disease or disability (asked in 1 item) was negatively associated with total walking time $(r=-0.11)$.

After adjustment for all other individual determinants in the regression model (partial correlations), it appeared that only the quality of life and the attitude towards walking remained positive (and significant) associated with total walking time of the respondents. Other individual determinants were no longer significantly associated with total walking time. The (statistical) variance in the total walking time of the respondents in their neighborhood could so be explained for $8 \%$.

Social environmental determinants. Having social contacts was positively correlated with total walking time ( $r$
$=0.15$, see Table 2). After adjustment for individual determinants, social contacts still remained significantly associated with walking time (partial $r=0.12$ ). Total explained variance was $1 \%$.

Physical environmental determinants. The top five aspects of the neighborhood which the respondents were not satisfied with, were: waste, litter and dog waste (41\%), bad maintenance of pavements (39\%), vandalism (37\%), theft/robbery (29\%) and lack of benches (29\%).

The analysis showed no clear correlation between the degree of satisfaction with the physical environment and the total walking time. Older people who had a lower satisfaction with regard to waste, litter and/or dog waste ( $r=-0.12)$ and the population demographics $(r=-0.11)$, walked more minutes in the neighborhood than those with higher satisfaction scores on these items. If the variables on the physical environment were added to the blocks with individual and social environmental determinants, these variables add $2 \%$ to the explained variance (due to the (dis)satisfaction with the population demographics (partial $r=-0.14$ )).

Walking model. In total, the model for walking in the neighborhood including the frequency and duration of walking outside the neighborhood (partial $r=0.20$, respectively 0.14 ), explained $20 \%$ of the statistical variance in the total weekly walking time.

\section{DISCUSSION}

The current study examined the added value of perceived social and physical environmental determinants in addition to individual determinants in an explanatory model of total weekly walking time of older people living in neighborhoods in a Dutch town. Our final model explained $20 \%$ of the variance in total walking time in the neighborhood. Walking by older persons in the neighborhood is best predicted by the perceived quality of life and the frequency of walking outside the neighborhood (as a measure of readiness for walking, but this was of course actually a confounder). To a lesser extent, having a positive attitude, more social contacts and dissatisfaction with the population demographics also predicted the variance in walking.

The analysis showed that the model where all variables are examined in conjunction, gives insights in addition to the univariate associations. Conclusion is that perceived environmental determinants played only a minor role in predicting walking time.

For a study in the same population described elsewhere $[17,18]$ a subgroup of respondents kept a walking diary for a week. They drawn on a map their routes and the reason for walking there. They also marked the places that were perceived as attractive and unattractive for walking and the reasons why. Analyses of the diary 
Table 2. Stepwise linear regression ( $\mathrm{N}=411$ - 525; pairwise case deletion), dependent variable: walking in the neighborhood (sum score in minutes: range 0 - 870).

\begin{tabular}{|c|c|c|c|c|}
\hline Independent variables & $\begin{array}{l}\text { Univariate correlation } \\
\text { walking in } \\
\text { neighborhood }\end{array}$ & $\begin{array}{c}\text { Partial correlation } \\
\text { walking in neighborhood } \\
\text { (within block, cumulative) }\end{array}$ & $\begin{array}{l}\text { Partial correlation walking } \\
\text { in the neighborhood } \\
\text { (over all blocks) }\end{array}$ & $\mathrm{R}^{2}$ \\
\hline Individual determinants & & & & 0.08 \\
\hline Age (dummy < 65 vs $65-70$ yrs) & 0.05 & 0.05 & & \\
\hline Age (dummy < 65 vs $>70$ yrs) & 0.01 & 0.07 & & \\
\hline Gender (female = 2) & 0.00 & 0.04 & & \\
\hline Ethnicity & 0.05 & 0.08 & & \\
\hline Marital status (living alone vs living together) & $0.07^{*}$ & 0.06 & & \\
\hline Education (dummy low vs middle) & $-0.09^{*}$ & -0.09 & & \\
\hline Education (dummy low vs high) & -0.03 & -0.08 & & \\
\hline Quality of Life (RAND 36 scale score) & $0.22^{* *}$ & $0.21^{* *}$ & $0.13^{*}$ & \\
\hline Perceived health & $0.13^{* *}$ & 0.03 & & \\
\hline Use of mobility tools & $-0.09^{*}$ & 0.03 & & \\
\hline Long-term illness disorders disability & $-0.11^{* *}$ & 0.05 & & \\
\hline Discomfort when walking (sum score) & $-0.09^{* *}$ & 0.04 & & \\
\hline Attitude on walking & $0.19^{* *}$ & $0.18^{* *}$ & $0.12^{*}$ & \\
\hline Social norm on walking & $0.11^{* *}$ & 0.08 & & \\
\hline Intention on walking & $0.08^{*}$ & 0.00 & & \\
\hline Knowledge on physical activity benefits (sum score) & 0.05 & -0.03 & & \\
\hline Dog owner & 0.02 & 0.00 & & \\
\hline Social environment & & & & 0.01 \\
\hline Social contacts & $0.15^{* *}$ & $0.12^{*}$ & $0.10^{*}$ & \\
\hline Loneliness & -0.01 & 0.04 & & \\
\hline Physical environment & & & & 0.02 \\
\hline Attractiveness of the neighborhood & 0.03 & 0.05 & & \\
\hline Satisfaction (Sat.) with parks/trees & -0.02 & 0.02 & & \\
\hline Sat. Streetlights & 0.04 & 0.06 & & \\
\hline Sat. Type of buildings & -0.02 & 0.01 & & \\
\hline Sat. Presence of benches & -0.03 & -0.03 & & \\
\hline Sat. Noises (outside) of residents & -0.04 & 0.00 & & \\
\hline Sat. Noise and traffic & -0.07 & -0.02 & & \\
\hline Sat. Dust/soot/smoke by traffic & -0.07 & -0.07 & & \\
\hline Sat. Dust/soot/smoke by industry & -0.02 & -0.01 & & \\
\hline Sat. Maintenance of housing & -0.04 & 0.04 & & \\
\hline Sat. Waste/litter/dog waste & $-0.12^{* *}$ & -0.05 & & \\
\hline Sat. Smell/odor & $-0.11^{*}$ & -0.09 & & \\
\hline
\end{tabular}




\begin{tabular}{|c|c|c|c|c|}
\hline \multicolumn{5}{|l|}{ Continued } \\
\hline Sat. Surface water quality & 0.01 & -0.04 & & \\
\hline Sat. Traffic safety & $-0.09^{*}$ & -0.05 & & \\
\hline Sat. Road maintenance & -0.02 & -0.02 & & \\
\hline Sat. Maintenance of sidewalks & -0.05 & -0.04 & & \\
\hline Sat. Crossings/thresholds/stairs & -0.01 & -0.03 & & \\
\hline Sat. Demographics & $-0.11^{* *}$ & $-0.14^{* *}$ & $-0.10^{*}$ & \\
\hline Walking in the neighborhoodM & & & & 0.09 \\
\hline Stage of change walking & $0.52^{* *}$ & n.i.m. $r>0.5$ & & \\
\hline Frequency walking in the neighborhood & $0.86^{* *}$ & n.i.m. $r>0.5$ & & \\
\hline Frequency walking outside neighb^^ & $0.33^{* *}$ & $0.28^{* *}$ & $0.20^{* *}$ & \\
\hline Frequency walking in and outside the neighborhood & $0.85^{* *}$ & n.i.m. $r>0.5$ & & \\
\hline Duration walking in the neighborhood & $0.77^{* *}$ & n.i.m. $r>0.5$ & & \\
\hline Duration walking outside the neighborhood & $0.32^{* *}$ & 0.14 & $0.14^{* *}$ & \\
\hline Duration walking in and outside the neighborhood & $0.69^{* *}$ & n.i.m. $r>0.5$ & & \\
\hline Total explained variance & & & & 0.20 \\
\hline
\end{tabular}

and observations by the researchers showed that objectively measured physical environmental characteristics, such as the presence of shops, stairs, green spaces and the bustle of the roads were associated with the route choice and the attractiveness of walking trails. Evidence also shows that people especially walk routes that lead to stores and shopping centers.

Our conclusion is consistent with a recent publication by De Melo et al. [19], who also found that especially personal and intrinsic features predict walking behavior of older people, and that the perceived environment predicts relatively less. Our study gives a valuable addition to the work of Nagel et al. [20] and Sallis et al. [21], because we added behavioral individual determinants, which explained considerable more variation in walking time than the build environmental variables did.

A disadvantage of our study is that questionnaires were self reported, so bias may be occurred in the actual walking time. In future studies, more objective measures such as accelerometers and global positioning system should be used (as a very recent example we mention Carlson et al. [22]). However, this was for us not feasible because of the costs and practical issues. By asking the walking behavior for several purposes and in both duration and frequency and taking summed scores, a best guess was made. Another limitation of the study was its cross-sectional nature, therefore no conclusions about the direction of the relationships could be given. Although common in a survey in the municipality of Schiedam, the response rate (32\%) was rather low. It may be that a selection has occurred, probably from people who regularly walk and felt more appealed by the subject.

For both age and level of education, we worked with dummy variables in the model because the relationships with walking time were not linear. Both the youngest and the oldest respondents walked less in the neighborhood than the group between 65 and 70 years. This may be related to the retirement phase where people have more free time. Later in life one generally gets more mobility problems. Both the respondents with the lowest and highest education categories walked more than the middle group. Perhaps this has to do with the need to the first group and walking for health by the second (highest education)?

Since attitude towards walking explained most of the variance it seems important to increase attitude through education and counseling, to convince older people (even in the case of physical disability) that walking is a healthy and feasible form of physical activity. A recent study by Temple et al. [23], unveiled that owning a dog serves as a motivational support for walking practice, even is the weather is bad.

Research by Stiggelbout et al. [24] shows that "Fun and relaxation", "Competition", and "Health and Care" 
are the three main motivations of older people to start (sportive) physical activities. That study also indicates that "Sportive Walking" fit in all these groups and thus is an easy accessible activity that can potentially appeal to many older people. Such kind of walking interventions as a group activity could perhaps be organized in neighborhoods in towns to increase the number of older people motivated for walking.

In summary it was concluded that individual and social determinants predicted the most variance in walking time and that perceived environmental determinants played only a minor role. Health promotion actions may benefit from these insights.

\section{ACKNOWLEDGEMENTS}

This project was funded by Zonmw (Netherlands Organization for Health Research and Development) grant number 4005.0002. Thanks to the Municipality of Schiedam for the willing cooperation.

\section{REFERENCES}

[1] Nelson, M.E., Rejeski, W.J., Blair, S.N., Duncan, P.W., Judge, J.O., King, A.C, et al. (2007) Physical activity and public health in older adults: Recommendation from the American College of Sports Medicine and the American Heart Association. Medicine \& Science in Sports \& Exercise, 39, 1435-1445. doi:10.1249/mss.0b013e3180616aa2

[2] Chodzko-Zajko, W.J., Proctor, D.N., Fiatarone Singh, M.A., Minson, C.T., Nigg, C.R., Salem, G.J., et al. (2009) American College of Sports Medicine position stand. Exercise and physical activity for older adults. Medicine \& Science in Sports \& Exercise, 41, 1510-1530. doi:10.1249/MSS.0b013e3181a0c95c

[3] Christmas, C. and Andersen, R.A. (2000) Exercise and older patients: Guidelines for the clinician. Journal of the American Geriatric Society, 48, 318-324.

[4] Etnier, J.L., Nowell, P.M., Landers, D.M. and Sibley, B.A. (2006) A meta-regression to examine the relationship between aerobic fitness and cognitive performance. Brain Research Reviews, 52, 119-130. doi:10.1016/j.brainresrev.2006.01.002

[5] Van Uffelen, J.G.Z., Chin A.P., J.M., Marijke, HopmanRock, M. and van Mechelen, W. (2008) The effects of exercise on cognition in older adults with and without cognitive decline: A systematic review. Clinical Journal of Sport Medicine, 18, 486-500. doi:10.1097/JSM.0b013e3181845f0b

[6] Yaffe, K., Barnes, D., Nevitt, M., Lui, L.Y. and Covinsky, K. (2001) A prospective study of physical activity and cognitive decline in elderly women: Women who walk. Archives of Internal Medicine, 161, 1703-1708. doi:10.1001/archinte.161.14.1703

[7] Netz, Y., Wu, M., Becker, B.J. and Tenenbaum, G. (2005) Physical activity and psychological well-being in advanced age: A meta-analysis of intervention studies. Psychology \& Aging, 20, 272-284.

\section{doi:10.1037/0882-7974.20.2.272}

[8] Miller, M.E., Rejeski, W.J., Reboussin, B.A., Ten Have, T.R. and Ettinger, W.H. (2000) Physical activity, functional limitations, and disability in older adults. Journal of the American Geriatric Society, 48, 1264-1272.

[9] Nusselder, W.J., Looman, C.W., Franco, O.H., Peeters, A., Slingerland, A.S. and Mackenbach, J.P. (2008) The relation between non-occupational physical activity and years lived with and without disability. Journal of Epidemiology \& Community Health, 62, 823-828. doi:10.1136/jech.2007.067165

[10] Kemper, H.C.G., Ooijendijk, W.T.M. and Stiggelbout, M. (2000) Consensus on the Dutch standard of healthy exercise. Tijdschrift voor Gezondheidswetenschappen/TSG, 78, 180-183.

[11] Hildebrandt, V., Chorus, A.M.J. and Stubbe, J.H. (2010) Trend report physical activity and health 2008/2009. TNO Kwaliteit van Leven, Leiden.

[12] Fisher, K.J., Pickering, A. and Li, F. (2002) Healthy aging through active leisure: Design and methods of SHAPEA randomized controlled trial of a neighborhood-based walking project. World Leisure, 1, 19-28. doi:10.1080/04419057.2002.9674257

[13] Sallis, J., Owen, N. and Fisher, E. (2000) Ecological Models of health behavior. In: Glanz, K., Rimer, B. and Viswanath, K., Eds., Health Behavior and Health Education: Theory, Research, and Practice, 4th Edition, JosseyBass United States, 465-482.

[14] Trost, S.G., Owen, N., Bauman, A.E., Sallis, J.F. and Brown, W. (2002) Correlates of adults' participation in physical activity: Review and update. Medicine \& Science in Sports \& Exercise, 34, 1996-2001. doi:10.1097/00005768-200212000-00020

[15] Morgan, D. and O’Brien, K. (1993) Improving survey questionnaires through focus groups. In: Morgan, D., Ed., Successful Focus Groups: Advancing the State of the Art, Sage, London, 105-118.

[16] Van der Zee, K.I. and Sanderman, R. (1993) Measuring general health with the RAND-36. A manual. Noordelijk centrum voor gezondheidsvraagstukken, Groningen.

[17] Borst, H.C., de Vries, S.I., Graham, J.M.A., van Dongen, J.E., Bakker, I. and Miedema, H.M.E. (2009) Influence of environmental street characteristics on walking route choice of elderly people. Journal of Environmental Psychology, 29, 477-484. doi:10.1016/j.jenvp.2009.08.002

[18] Borst, H.C., Miedema, H.M.E., de Vries, S.I., Graham, J.M.A. and van Dongen, J.E.F. (2008) Relationships between street characteristics and perceived attractiveness for walking reported by elderly people. Journal of Environmental Psychology, 28, 353-361. doi:10.1016/j.jenvp.2008.02.010

[19] De Melo, L.L., Menec, V., Porter, M.M. and Ready, A.E. (2010) Personal factors, perceived environment, and objectively measured walking in old age. Journal of Aging and Physical Activity, 18, 280-292.

[20] Nagel, C.L., Carlson, N.E., Bosworth, M. and Michael, Y.L. (2008) The relation between neighborhood built environment and walking activity among older adults. Ameri- 
can Journal of Epidemiology, 15, 461-468. doi:10.1093/aje/kwn158

[21] Sallis, F.J., Bowles, H.R., Bauman, A., Ainsworth, B.E., Bull, F.C., Craig, C.L., et al. (2009) Neighborhood environments and physical activity among adults in 11 countries. American Journal of Preventive Medicine, 36, 484490. doi:10.1016/j.amepre.2009.01.031

[22] Carlson, J.A., Sallis, J.F., Conway, T.L., Saelens, B.E., Frank, L.D., Kerr, J., et al. (2011) Interactions between psychosocial and built environment factors in explaining older adults' physical activity. Preventive Medicine, 54 68-73. doi:10.1016/j.ypmed.2011.10.004

[23] Temple, V., Rhodes, R. and Hoggins, J.W. (2011) Unleashing physical activity: An observational study of park use, dog walking, and physical activity. Journal of Physical Activity \& Health, 8, 766-774.

[24] Stiggelbout, M., Hopman-Rock, M. and van Mechelen, W. (2008) Entry correlates and motivations of older adults participating in organized exercise programs. Journal of Aging and Physical Activity, 16, 342-354. 